\title{
The Ahmed Glaucoma Valve in Refractory Glaucoma: Experiences in Southwest Ethiopia
}

\author{
Girum W. Gessesse
}

\begin{abstract}
BACKGROUND: The management of refractory glaucoma is a challenging task for any glaucoma surgeon. This study is aimed to evaluate the efficacy of Ahmed Glaucoma Valve implantation in refractory glaucomas in South-West Ethiopia.

METHODS: A retrospective review was conducted on the charts of consecutive patients treated with Ahmed glaucoma valve implantation at Jimma University Specialized Hospital between August 2012 and August 2014. Success was defined as Intraocular Pressure (IOP) less than $22 \mathrm{~mm} \mathrm{Hg}$ and greater than $5 \mathrm{~mm} \mathrm{Hg}$ at 6 months, with at least 30\% reduction from baseline, without medical therapy (complete success) or either with or without medication (qualified successes)..

RESULTS: A total of 12 eyes of 11 patients were included. The mean age of patients was 40.7 (SD=19.0) years; $63.6 \%$ of them were males. The main types of glaucoma were pseudoexfoliative (3 eyes), uveitic (2 eyes), chronic angle closure (2 eyes) and Juvenile Open Angle (JOAG) (2 eyes). The mean IOP was reduced from preoperative level $(32.75 \pm 7.14 \mathrm{mmHg})$ to $(15.75 \pm 4.35 \mathrm{mmHg})$ at six postoperative months, (P<0.001); 66.7\% eyes had complete successes while $83.3 \%$ had qualified success. Intra- operative complications were encountered in $2(16.7 \%)$ eyes, while $5 / 12(41.7 \%)$ eyes had post-operative complications-hypotony (one with choroidal effusion) and progression of cataract in 2 eyes each. Hypertensive phase was diagnosed in 2(16.7\%) eyes.

CONCLUSION: The Ahmed glaucoma valve implant appears to be effective and relatively safe for treating complicated glaucomas with success rate comparable with those reported from other studies.

KEYWORDS: Ahmed glaucoma valve, refractory glaucoma, complications, Ethiopia
\end{abstract}

DOI: http://dx.doi.org/10.4314/ejhs.v25i3.10

\section{INTRODUCTION}

Africa is a region with the highest prevalence of glaucoma $(1,2)$, and most patients present with advanced stage of the disease or unilateral blindness with high intraocular pressure (IOP) (3). Glaucoma filtration procedures (Trabeculectomy) are commonly required for IOP control and preservation of vision. The African race is also associated with higher rate of failure of trabeculectomy (4). It is always a challenge for ophthalmologists in the region in dealing with such failed cases of trabeculectomy and other complex secondary glaucomas.

Glaucoma drainage devices (GDD) are generally used for such refractory cases where conventional surgery has failed or is likely to fail; these also include uveitic glaucoma, neovascular glaucoma, previous ocular surgery or other conditions associated with conjunctival scarring. The plates of glaucoma implants offer a large surface area reservoir for the drainage of aqueous humor and prevent excessive scar tissue formation at the limbus (5).

GDD include the open tube drainage devices like Molteno implant, the Baerveldt implant and the Schocket tube shunt, and the flow-restrictive drainage devices like the Krupin and the Ahmed Glaucoma Valve (AGV) implants (6). Restrictive devices contain a valve that is designed to reduce the incidence of postoperative hypotony, while offering the benefit of immediate pressure reduction. The AGV is being widely used throughout the world since its introduction in 1993 (7).

\footnotetext{
${ }^{1}$ Department of Ophthalmology, Jimma University, Ethiopia

Corresponding Author: Grum W. Gessesse, Email: girumgw@yahoo.com
} 
There is a scarcity of data on the outcome of GDD surgery in Africa. Studying the outcomes of these types of surgeries is important as a quality control and to compare results with experience in other areas. It will also serve as a baseline for future interventions. In a retrospective case series investigating, the outcomes of AGV among 25 eyes of children and adult patients in Kenya, Kiage et al reported $79 \%$ success and $53.3 \%$ mean IOP reduction at 2 a months' follow-up (8). A recent retrospective review of 13 eyes of 12 patients who underwent this surgery in Central Ethiopia showed a success rate of IOP controlling of $76.9 \%$ (9). The current study was carried out to describe the initial experience of AGV implant surgery in a tertiary hospital in Southwest Ethiopia.

\section{PATIENTS AND METHODS}

This is a retrospective review of the medical records of patients with refractory glaucoma who underwent isolated tube shunt surgery using AGV in the Department of Ophthalmology, Jimma University Specialized Hospital, between August 2012 and August 2014. Patients who had completed postoperative follow-up of 6 months and for whom IOP was taken at baseline and during the follow-up period were included. All eyes had glaucoma, which could not be controlled by medications and/or previous glaucoma surgery. The diagnosis of glaucoma was based on the IOP, characteristic optic nerve pathology with or without visual field changes.

A predesigned format was used to retrieve clinical information from the charts which included age and sex of the patients, type of glaucoma, previous ocular surgery, current surgical procedure and pre- and post-operative visual acuity (VA), IOP and glaucoma medications. IOP was measured using Goldman applanation tonometer mounted on slit lamp or iCare rebound tonometer (iCare Finland, Helsinki, Finland). Postoperative IOP taken at $1^{\text {st }}$ week as well as $1^{\text {st }}, 2^{\text {nd }}$ and $6^{\text {th }}$ month postoperative periods were included. Any intraoperative and postoperative complication was also noted. The clinical data was collected by a senior ophthalmology resident in the department and the author; all surgical procedures were performed by the same surgeon (GG).

Surgical method: General steps followed in the procedure are described elsewhere (6). In this series, AGV consisting of a silicone tube connected to a silicone reservoir plate (FP7 or FP8 models) [New World Medical Inc., Rancho Cucamonga, California] was used (6). Model FP7 with large surface area of $184 \mathrm{~mm}^{2}$ was inserted in 11 eyes and model FP8 with surface area of $96 \mathrm{~mm}^{2}$ in 1 eye. Surgery was performed using retro-bulbar or sub-tenon anesthesia. AGV was implanted in the upper temporal fornix in all cases, 9-0 nylon was used to suture the implant to the sclera, and either human sclera or cornea was used to cover the tube near the limbus.

Definition of success and failure: The primary outcome variable for success was postoperative IOP control in 6 months, i.e. IOP less than $22 \mathrm{mmHg}$ and more than $5 \mathrm{mmHg}$ with at least $30 \%$ reduction from the preoperative level in the absence of devastating ocular complications. Eyes that met the above criteria and were not on supplemental anti-glaucoma medical therapy were defined as complete successes and those that met the criteria either with or without supplemental medical therapy were defined as qualified successes. Hypotony was defined as IOP less than or equal to $5 \mathrm{~mm} \mathrm{Hg}$ on any post-operative visit. Hypertensive phase (HP) was defined as an IOP measurement of greater than $21 \mathrm{mmHg}$ (with or without medications) during the 6-month postoperative period that was not a result of tube obstruction, retraction or malfunction. Resolution of this phase was IOP of less than $22 \mathrm{mmHg}$ along with a reduction of the IOP by $3 \mathrm{mmHg}$ or more with the same or less number of medications (10). Cataract was considered to have progressed if there was loss of 2 lines of Snellen VA that was attributed to cataract at the six-month follow-up visit.

Clinical data was analyzed using SPSS software for Windows Version 16 (IBM Corp., New York, NY, USA). Simple descriptive statistics (frequency, mean, percentage) were used to describe the study variables. The difference of the mean postoperative IOP was compared from baseline level using student's t-test. Due to the sample size,advanced statistical methods are not used to look for possible factors associated with success and failure of the procedure.

Ethical clearance: The study was done with adherence to the guidelines of the Declaration of Helsinki. Ethical clearance was obtained from the Department of Ophthalmology, College of Public Health and Medical Sciences, Jimma University. As part of our routine practice, patients provided 
written consent preoperatively after the purpose of the surgery, expected outcomes, possible complications and postoperative care had been explained to them. Clinical data were retrieved with no identifier of the patients.

\section{RESULTS}

A total of 19 eyes of 18 patients underwent AGV implant surgery during the specified period. Two patients (2 eyes) who did not have follow-up beyond the first postoperative month and 2 children (3 eyes) (less than 4 years of age) were excluded. Two charts could notbe retrieved. Therefore, data of 12 eyes of 11 patients were included in this study.

The mean age of patients was 40.7 (SD = 19.0) years (range $=12-67$ years); $63.6 \%$ were males. The most common diagnosis was pseudoexfoliative glaucoma (3 eyes) followed by uveitic glaucoma, Juvenile Open Angle Glaucoma (JOAG) and chronic angle closure glaucoma (2 eyes each). Primary Open Angle Glaucoma (POAG), traumatic and silicone oil induced glaucoma were diagnosed in 1 eye each. About
$75 \%$ of eyes had advanced glaucoma with vertical cup-disc ratio of 0.85 and above; and $83 \%$ of eyes had one or more intraocular surgery or laser treatment performed before the current implant, the average being 1.58 per eye (see table 1 ). The types of glaucoma medication used included: Timolol $0.5 \%$, Pilocarpine 4\%, Latanoprost $0.005 \%$ (Xalatan), Bimatoprost $0.03 \%$ (Lumigan) and oral Acetazolamide.

The mean (SD) preoperative IOP was $32.75(7.14) \mathrm{mmHg}$, the mean IOP at 6 month was 15.75 (4.35) $\mathrm{mmHg}$, with $51.9 \%$ reduction from baseline. This was statistically significant $(\mathrm{P}<0.001)$. The mean postoperative IOP was lower than the baseline level for all individual postoperative periods; 9.36(4.41), 15.58(7.18), $16.36(4.78)$ and $15.75(4.35)$ at first the week, first, second and $6^{\text {th }}$ months respectively (see Fig 1 and table 2). According to the study definition, 8/12 eyes $(66.7 \%)$ had complete success while $10 / 12$ eyes $(83.3 \%)$ had qualified success at 6 month. The mean number of medications was reduced from 2.1 preoperatively to 0.33 at 6 month, with the use of acetazolamide tablets reduced from $72.7 \%$ to 0 .

Table 1: Characteristics of patients treated with Ahmed glaucoma valve implant surgery, Department of Ophthalmology, Jimma University Specialized Hospital, Ethiopia, August 2012- August 2014.

\begin{tabular}{|c|c|c|c|c|c|c|c|c|}
\hline $\begin{array}{l}\text { Case } \\
\text { No }\end{array}$ & Age/Sex & Eye & $\begin{array}{l}\text { Preoperative } \\
\text { Visual } \\
\text { Acuity }\end{array}$ & $\begin{array}{l}\text { Preoperative } \\
(\mathrm{mmHg})\end{array}$ & IOP & $\begin{array}{l}\text { Type } \\
\text { Glaucoma }\end{array}$ & of & Previous Intervention \\
\hline 1 & $65 \mathrm{M}$ & OD & $6 / 18$ & 30 & & POAG & & Trabeculectomy \\
\hline 2 & $23 \mathrm{M}$ & OS & $3 / 60$ & 28 & & JOAG & & Trabeculectomy \\
\hline 3 & $12 \mathrm{M}$ & OS & $6 / 36$ & 38 & & Traumatic & & SICS PC IOL; LPI \\
\hline 4 & $35 \mathrm{M}$ & OS & $3 / 60$ & 31 & & JOAG & & $\begin{array}{l}\text { Trabeculectomy (twice); } \\
\text { needling MMC }\end{array}$ \\
\hline 5 & $55 \mathrm{~F}$ & OD & $6 / 9$ & 23 & & PXG & & DLT; SICS PC IOL \\
\hline 6 & $67 \mathrm{M}$ & OS & $3 / 60$ & 28 & & PXG & & SICS PC IOL \\
\hline 7 & $35 \mathrm{~F}$ & OS & $1 / 60$ & 36 & & CACG & & Trabeculectomy; needling \\
\hline 8 & $60 \mathrm{M}$ & OS & $6 / 18$ & 26 & & PXG & & $\begin{array}{l}\text { Trabeculectomy MMC; } \\
\text { needling; DLT }\end{array}$ \\
\hline 9 & $43 \mathrm{M}$ & OS & $2 / 60$ & 33 & & $\begin{array}{l}\text { Silicone } \\
\text { induced }\end{array}$ & oil & $\begin{array}{l}\text { PPV, Endolaser, Silicone oil; } \\
\text { SICS PC IOL }\end{array}$ \\
\hline 10 & $35 \mathrm{~F}$ & OS & $\mathrm{HM}$ & 32 & & CACG & & Trabeculectomy; needling \\
\hline \multirow[t]{2}{*}{11} & $18 \mathrm{~F}$ & OD & $6 / 36$ & 38 & & Uveitic & & None \\
\hline & & OS & $6 / 36$ & 50 & & Uveitic & & None \\
\hline
\end{tabular}

IOP: Intraocular Pressure; POAG: Primary open angle glaucoma; PXG: Pseudoexfoliative glaucoma; CACG: Chronic Angle Closure Glaucoma; JOAG: Juvenile Open Angle Glaucoma; SICS PC IOL: Manual small incision cataract surgery with posterior chamber lens; MMC: Mitomycin C; LPI; Laser peripheral Iridotomy: PPV: Pars Plana Vitrectomy; DLT: Diode Laser Trabeculoplasty; OD: Right Eye; OS: Left Eye; HM: Hand Motion 
Intra-operative complications were encountered in 2(16.7\%) eyes: conjunctival button hole that required suturing and leakage of Silicone oil into the anterior chamber in another post-vitrectomized eye. A total of 7 post-operative complications were recorded in $5(41.7 \%)$ eyes; hypotony occurred in $2(16.7 \%)$ eyes, one with choroidal effusion that resolved spontaneously. Two eyes (16.7\%) had progression of cataract; one of them also had tube iris touch. Partial tube obstruction occurred in one eye (see table 2). Hypertensive phase was diagnosed in 2 eyes at first and third post-operative months; both had resolution of this phase with glaucoma medication.

VA remained the same or within one line in 7 $(58.3 \%)$ eyes while worsened by two lines or more in $2(16.7 \%)$ eyes, and improved by two lines in $3(25.0 \%)$ eyes.

Table 2: Postoperative clinical profile of patients treated with Ahmed glaucoma valve implant surgery, Department of Ophthalmology, Jimma University Specialized Hospital, Ethiopia, August 2012- August 2014.

\begin{tabular}{ccccccl}
\hline $\begin{array}{c}\text { Case } \\
\text { No }\end{array}$ & \multicolumn{3}{c}{ Intraocular Pressure (mmHg) } & $\begin{array}{c}\text { Visual } \\
\text { Acuity } \\
\text { (Month 6) }\end{array}$ & Post-operative Complication \\
\cline { 2 - 5 } & Week 1 & Month 1 & Month2 & Month 6 & $6 / 36$ & $\begin{array}{l}\text { Tube iris touch; Progression of } \\
\text { cataract }\end{array}$ \\
\hline 1 & 9 & 10 & 12 & 10 & & \\
2 & 13 & 17 & 21 & 14 & $3 / 60$ & Hypotony and Choroidal effusion \\
3 & 3 & 9 & 7 & 15 & $6 / 18$ & \\
4 & - & 18 & 10 & 20 & $6 / 24$ & Hypotony \\
5 & 4 & 15 & 14 & 19 & $6 / 9$ & \\
6 & 12 & 16 & 15 & 18 & $4 / 60$ & \\
7 & 10 & 10 & - & 12 & $1 / 60$ & \\
8 & 10 & 15 & 19 & 11 & $6 / 36$ & Progression of cataract \\
9 & 18 & 17 & 17 & 22 & $2 / 60$ & Partial tube obstruction \\
10 & 12 & 10 & 12 & 10 & $1 / 60$ & \\
11. OD & 6 & 14 & 14 & 17 & $6 / 24$ & \\
OS & 6 & 36 & 17 & 21 & $6 / 24$ & \\
\hline
\end{tabular}

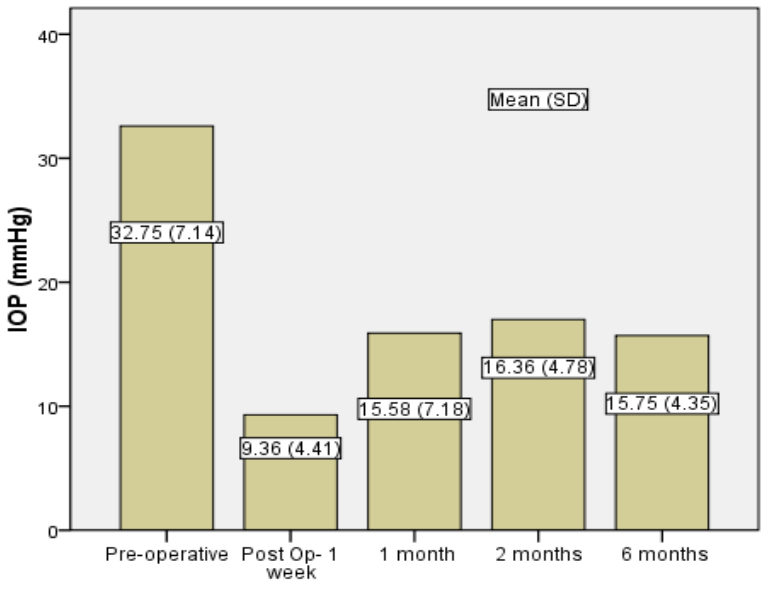

Figure 1: Pre-operative and postoperative mean intraocular pressure ; IOP: Intraocular Pressure; Post Op: post-operative; SD: Standard Deviation.

\section{DISCUSSION}

The probability of success of AGV implant surgeries reported in the literature varies due to differences in definition of success rate, in the follow-up period, the surgical technique, the type of implant used and the study population (particularly the glaucoma types).

In the present study, the mean IOP was reduced by $51.9 \%$ from the baseline of 32.75 \pm 7.14 to $15.75 \pm 4.35$ at 6 month; $8 / 12$ eyes $(66.7 \%)$ had complete successes while 10/12 eyes $(83.3 \%)$ had qualified success. This is in agreement with outcomes reported in the literature. A success rate of $76.9 \%$ at 6 month was reported in another study from Ethiopia (9), while a $79 \%$ success in a 2 months' follow-up has been reported among patients from Kenya 
(using iCare and Goldman applanation tonometers) (8). A cumulative probability of success ranging from $66 \%$ - 94\% at 12 month has also been reported from Asia and other regions of the world $(5,11-14)$.

The efficacy of a glaucoma surgery in reducing IOP must be interpreted in the context of its adverse events, with evaluation of the incidence and severity of associated complications (15). In our series, intraoperative and postoperative complications were encountered in 2/12(16.7\%) and $5 / 12(41.7 \%)$ eyes respectively; acceleration of cataract, hypotony, choroidal effusion and tube iris touch are among the commonly reported postoperative complications. No major complications related with tube (erosion, exposure, corneal touch) or devastating ocular complications, requiring secondary intervention, were also encountered. The visual deterioration observed in two eyes was explained by the progression of cataract. The overall intraoperative complication rate reported from the Ahmed Baerveldt Comparison (ABC) study was $10 \%$ (16). In the Ahmed Versus Baerveldt study (17) and the ABC Study, $45 \%$ and $43 \%$ of patients in the AGV arm/group experienced postoperative complications respectively. Complications reported in these studies were similar to those we encountered in our series. Three eyes had improvement of two lines or more of VA, and this is explained by clearing of corneal edema postoperatively in all cases.

Following GDD surgeries, a hypertensive phase (HP) can develop between 4 and 16 weeks postoperatively, during which IOP may rise into the high 20 s or 30 s (10). HP was diagnosed in $2 / 12(16.6 \%)$ of our series, at the $1^{\text {st }}$ and third months postoperatively. This is similar to a reported prevalence of $15.8 \%$ and $18.4 \%$ of patients in AGV group at the $3^{\text {rd }}$ and $6^{\text {th }}$ months respectively (18), while it has been identified in up to $63.2 \%$ of patients $(10,19)$. On the other hand, some studies did not find this hypertensive phase (5), including series of patients with uveitic glaucoma (12). The AGV is said to be associated with a higher incidence of the HP, which peaked at the $1^{\text {st }}$ month and stabilized by 6 months after the operation (20-21). This course goes in line with our experience.

It has been hypothesized that the implant type, material and surface area may affect the degree of IOP reduction, with a small retrospective comparison suggesting that the FP7model lower IOP more than the S2 model does (22), and a review of implants shows that large end plates achieve greater pressure reduction (23). While we used implants with silicone tubes and plates for all of our patients and the only eye that received the small surface area FP8 model in our series is in the failure group, it is difficult to compare this with other studies or between groups due to small number of eyes studied.

The major limitation of this study is the small sample size and the short period of follow-up. Post-operative follow-up as well as follow-ups to prescribed medications are well-recognized problems in most parts of Africa (24). It can also be said that in such cases where patient follow-up and compliance is a concern, the AGV may have been wiser options to preserve vision due to a lesser rate of early post-operative complications and need for post-operative interventions (25). Despite these, we hope that this study reflects one arm of African experience on this novel surgical intervention.

In conclusion, Ahmed Glaucoma Valve implantation appears to be a safe and effective modality of treatment for complicated glaucoma in Ethiopians with an overall success at early stages comparable to those reported from other studies.

\section{ACKNOWLEDGEMENTS}

I am very grateful to Professor Karim Damji, Dr M. Dorey and Dr M. Edwards for their invaluable support during my fellowship, and New World Medical Inc [Dr A Mateen Ahmed] for donating the glaucoma valves. I would also like to thank Dr Kumale Tolesa for collecting the clinical data of patients.

\section{REFERENCES}

1. Ntim-Amponsah CT, Amoaku WM, OfosuAmaah S, et al. Prevalence of glaucoma in an African population. Eye (Lond) 2004; 18:491.

2. Tham YC, Li X, Wong TY, Quigley HA, Aung T, Cheng CY. Global Prevalence of Glaucoma and Projections of Glaucoma Burden through 2040: A Systematic Review and Meta-Analysis. Ophthalmology 2014;121 (11):2081-2090. 
3. Rotchford AP, Johnson GJ. Glaucoma in Zulus: A populationbased cross-sectional survey in a rural district in South Africa. Arch Ophthalmol 2002; 120:471-8.

4. Broadway D, Grierson I, Hitchings R. Racial differences in the results of glaucoma filtration surgery: Are racial differences in the conjunctival cell profile important? $\mathrm{Br} J$ Ophthalmol 1994; 78:466-75.

5. Das JC, Chaudhuri Z, Sharma P, Bhomaj S. The Ahmed Glaucoma Valve in Refractory Glaucoma: experiences in Indian Eyes. Eye 2005; 19, 183-190.

6. Allingham RR, Damji KF, Freedman S, et al. Glaucoma Drainage-Device Surgery. In: Shields Textbook of Glaucoma. 6th ed. Philadelphia, Lippincott Williams and Wilkins, 2011: 524-531.

7. Coleman AL, Hill R, Wilson MR, Choplin N, Kotas- Neumann $R$, Tam $M$, et al. Initial clinical experience with the Ahmed Glaucoma Valve implant. Am J Ophthalmol 1995; 120:23-31.

8. Kiage DO, Gradin D, Gichuhi S, Damji KF. Ahmed Glaucoma Valve Implant: Experience in East Africa. Middle East Afr J Ophthalmol 2009; 16: 151-55.

9. Giorgis AT. Initial clinical experience of tubeshunt surgery in Ethiopian patients with refractory glaucoma. Ethiop Med J 2012; 50:159-65.

10. Nouri-Mahdavi K, Caprioli J. Evaluation of the hypertensive phase after insertion of the Ahmed Glaucoma Valve. Am J Ophthalmol 2003; 136(6): 1001-1008.

11. Shah MR, Khandekar RB, Zutshi R, Mahrooqi R. Short term outcome of Ahmed glaucoma valve implantation in management of refractory glaucoma in a tertiary hospital in Oman. Oman J Ophthalmol 2013; 6: 27-32.

12. Ozdal PC, Vianna RN, Deschenes J. Ahmed valve implantation in glaucoma secondary to chronic uveitis. Eye 2006; 20: 178-183.

13. Tai MC, Cheng JH, Chen JT, Liang CM, Lu DW. Intermediate outcomes of Ahmed glaucoma valve surgery in Asian patients with intractable glaucoma. Eye 2010; 24(4):547-52.

14. Li Z, Zhou M, Wang W, et al. A prospective comparative study on neovascular glaucoma and nonneovascular refractory glaucoma following Ahmed glaucoma valve implantation. Chin Med J 2014;127 (8): 1417.

15. Gedde SJ, Herndon LW, Brandt JD, Budenz DL, et al. Surgical Complications in the Tube Versus Trabeculectomy Study During the First Year of Follow-up. Am J Ophthalmol 2007; 143: 23-31.

16. Budenz DL, Barton K, Feuer WJ, Schiffman J, Costa VP, Godfrey DG, et al. Treatment outcomes in the Ahmed Baerveldt Comparison Study after 1 year of follow-up. Ophthalmology 2011; 118:443-52.

17. Christakis PG, Kalenak JW, Zurakowski D, Tsai JC, Kammer JA, Harasymowycz PJ, Ahmed II. The Ahmed Versus Baerveldt study: one-year treatment outcomes. Ophthalmology. 2011;118(11):2180-9.

18. Shiu-Chen Wu, et al. Clinical Experience with the Ahmed Glaucoma Valve Implant in Complicated Glaucoma. Chang Gung Med J 2003;26:904-10.

19. Yalvac IS, Eksioglu U, Satana B, Duman S. Long-term results of Ahmed glaucoma valve and Molteno implant in neovascular glaucoma. Eye 2007; 21: 65-70.

20. Ayyla RS, Zurakowski D, Smith JA, Monshizadeh R, Netland PA, Richards DW, et al. A clinical study of the Ahmed Glaucoma Valve implant in advanced glaucoma. Ophthalmology 1998; 105:1968-76.

21. Ayyala RS, Zurakowski D, Monshizadeh R, et al. Comparison of double-plate Molteno and Ahmed glaucoma valve in patients with advanced uncontrolled glaucoma. Ophthalmic Surg Lasers 2001; 33:94-101.

22. Hinkle DM, Zurakowski D, Ayyala RS. A comparison of polypropylene plate Ahmed. Eur J Ophthalmol 2007; 17(5):696 -701.

23. Schwartz KS, Lee RK, Gedde SJ. Glaucoma drainage implants: a critical comparison of types. Curr Opin Ophthalmol 2006; 17:181.

24. Tamrat L, Gessesse GW, Gelaw Y. Adherence to topical glaucoma medications in Ethiopian patients. Middle East Afr J Ophthalmol 2015; 22:59-63.

25. Aminlari AE, Scott IU, Aref AA. Glaucoma Drainage Implant Surgery - An EvidenceBased Update with Relevance to Sub-Saharan Africa. Middle East Afr J Ophthalmol 2013; 20: 126-130. 